\title{
PENGARUH TINGKAT USABILITY DESAIN RESPONSIF WEB MOBILE PERGURUAN TINGGI TERHADAP PERSEPSI PENGGUNA
}

\author{
Fadliyani Nawir ${ }^{1}$, Achmad Syarief ${ }^{2}$ \& Irfansyah $^{3}$ \\ ${ }^{1}$ Program Studi Magister Desain Institut Teknologi Bandung \\ e-mail: lunlyhanie@gmail.com \\ 2 Program Studi Magister Desain Institut Teknologi Bandung \\ e-mail: asyarief.itb@gmail.com \\ ${ }^{3}$ Program Studi Magister Desain Institut Teknologi Bandung \\ e-mail: fandkv@yahoo.co.id
}

\begin{abstract}
Abstrak. Desain web responsif merupakan pendekatan yang menunjukkan desain dan pengembangan yang harus merespon perilaku pengguna dan lingkungan berdasarkan ukuran layar, platform, dan orientasi. Desain responsif yang diterapkan pada web perguruan tinggi ingin memberikan kemudahan dalam berinteraksi. Untuk mengukur bagaimana sebuah web dapat efektif, efisien dan membuat pengguna puas saat berinteraksi digunakan teori usability. Selain itu aspek kognitif juga dapat mempengaruhi proses penyampaian informasi melalui web. Penelitian ini bertujuan untuk mengidentifikasi pengaruh tingkat usability desain responsif web mobile perguruan tinggi terhadap persepsi pengguna. Objek penelitiannya adalah lima web mobile perguruan tinggi yaitu Universitas Indonesia, Institut Teknologi Bandung, Universitas Sebelas Maret, Universitas Padjajaran, dan Universitas Pendidikan Indonesia. Analisis secara kuantitatif terhadap tingkat usability kelima web mobile menunjukkan bahwa tingkat usability yang dimiliki oleh sebuah web mobile perguruan tinggi mempengaruhi tampilan visual web berdasarkan persepsi penggunanya. Tingkat usability memberikan pengaruh sebesar $67,1 \%$ terhadap persepsi pengguna melalui tampilan visual.
\end{abstract}

Kata kunci: Responsif desain web mobile, perguruan tinggi, usability, tampilan visual.

Abstract. Responsive web design is an approach that shows the design and development should respond to the user's behavior and environment based on screen size, platform and orientation. Responsive design that is applied to the web colleges want to provide ease in interacting. To measure how a website can be an effective, efficient and makes users satisfied when interacting used usability theory. Besides the cognitive aspects can also affect the process of 
delivering information over the web. This study aimed to identify the influence of the mobile web usability responsive design colleges to the perception of users. Objects are five mobile web research universities, namely the University of Indonesia, Bandung Institute of Technology, University of March, Padjadjaran University, and the University of Indonesia. Quantitative analysis of the level of the fifth mobile web usability shows that the level of usability that is owned by a mobile web college affect the visual appearance of a web based user perception. Usability level of $67.1 \%$ impact on the perception of the user through visual display.

Keywords: Responsive web design mobile, college, usability, visual display.

\section{Pendahuluan}

Desain web responsif merupakan pendekatan yang menunjukkan desain dan pengembangan yang harus merespon perilaku pengguna dan lingkungan berdasarkan ukuran layar, platform, dan orientasi. Desain responsif menjadi tren besar pada tahun 2013 di bidang desain web. Dengan perkembangan perangkat mobile, sudah seharusnya desainer dan pengembang untuk membuat web yang dapat diakses di berbagai ukuran layar pada perangkat mobile. Desain responsif menjadi solusi bagi sejumlah masalah dalam hal merek, dan merancang web berbasis responsif menghilangkan kebutuhan untuk membuat versi web mobile yang terpisah, menghemat waktu dan juga biaya. Desain responsif juga menyediakan pengalaman yang mulus bagi pengguna pada perangkat mobile, dan memberikan akses ke informasi yang pengguna butuhkan tidak peduli dengan ukuran layar pada perangkat mobile yang digunakan. Maka dari itu, pesan dari sebuah merek tersampaikan dengan baik ke pengguna melalui media web.

Kemendikbud (Kemendikbud, 2014:1) menyebutkan pada tahun 2014, siswa yang lulus Ujian Nasional sebanyak 1.624 .946 orang. Umumnya dari calon mahasiswa akan memilih untuk mendaftar ke Perguruan Tinggi Negeri yang mempunyai sejarah melahirkan lulusan terbaik di Indonesia. Dan untuk mengetahui informasi mengenai PTN tersebut, banyak media yang menjadi alat penyebarannya baik elektronik maupun cetak, salah satunya melalui web perguruan tinggi tersebut. Survei Google dan Ipsos MediaCT (Google, 2012: 6) menyatakan 50\% dari pengguna internet di Indonesia yang berusia 18 - 24 tahun mengakses web melalui smartphone dan berdomisili di kota kota besar. Dengan peningkatan yang sangat pesat ini, pihak perguruan tinggi mulai mengembangkan web mobile agar dapat mengakomodir kebutuhan pengguna akan informasi pada media web. Pada web perguruan tinggi di Indonesia, umumnya memilih desain web responsif sebagai solusi untuk memenuhi kebutuhan pengguna perangkat mobile. Namun kenyataannya sebagian dari pengguna masih menggunakan $p c$ untuk mengakses web perguruan tinggi, mereka bahkan tidak menyadari dan memahami 
perubahan yang terjadi pada web perguruan tinggi. Tetapi setelah mengakses web melalui smartphone baru mereka menyadari dampak fleksibilitas dari desain responsif yang diusung oleh web perguruan tinggi.

Terdapat perbedaan pada saat mengukur web pada perangkat mobile, bukan hanya efektif, efisien, dan rasa puas. Fokus yang lebih utama yaitu kebutuhan pengguna, karena ukuran dan ruang yang terbatas pada perangkat mobile. Bagaimana cara menyajikan informasi yang kompleks ke dalam ruang yang terbatas. Fokus awal ada pada antarmuka web, pola desain responsif menggunakan grid - grid yang dapat membuat beberapa kolom dalam web untuk menyesuaikan diri dengan ukuran layar perangkat mobile yang berbeda - beda. Pada web perguruan tinggi yang menggunakan desain web responsif umumnya berpola sama, tetapi bila diperhatikan lebih seksama ada perbedaan antara satu dengan yang lain. Aldrian Agusta dalam tesisnya menyatakan web institusi sudah mempunyai pola baku yang menjadi acuan untuk membangun web, termasuk perguruan tinggi. Tetapi dari segi konten dan elemen visual tiap perguruan tinggi merepresentasikan institusi masing-masing. Melalui evaluasi usability pada web perguruan tinggi diharapkan dapat meningkatkan kualitas perguruan tinggi itu sendiri dan dapat mengetahui kebutuhan pengguna dari sisi perangkat mobile agar dapat berkompetisi dengan perguruan tinggi yang lain.

Melihat penjabaran diatas, maka pertanyaan utama dari penelitian ini adalah bagaimana pengaruh tingkat usability terhadap persepsi pengguna responsif desain web mobile perguruan tinggi?

\section{Metode}

Penelitian ini menggunakan metode survei dengan kuesioner sebagai sumber data utama. Metode survei dipakai untuk mendapatkan data faktual tentang tingkat usability dan persepsi pengguna terhadap desain responsif web mobile perguruan tinggi. Untuk mengukur tingkat usability, peneliti membuat pernyataan berdasarkan pedoman usability web mobile Dan Seward. Untuk mengetahui persepsi pengguna, peneliti membuat pernyataan tentang bagaimana layout, warna, kontras mempengaruhi persepsi pengguna terhadap desain responsif web mobile perguruan tinggi dengan menggunakan beberapa kata sifat dan skala semantik diferensial. Data dari kuesioner tersebut akan dapat menggambarkan pengaruh tingkat usability desain responsif web mobile perguruan tinggi terhadap persepsi pengguna.

\begin{tabular}{|c|l|c|}
\hline No. & \multicolumn{1}{|c|}{ Pernyataan } & Kode \\
\hline \multicolumn{2}{|c|}{ Aspek designing for a goal } & A1 \\
\hline 1 & Menu yang diletakkan di bagian atas halaman web mudah diakses. & A2 \\
\hline 2 & Pilihan yang ada pada menu memudahkan untuk mencari informasi. & \\
\hline \multicolumn{2}{|c|}{ Aspek layout } & B1 \\
\hline 3 & Layout satu kolom memudahkan anda untuk berinteraksi dengan web. & B2 \\
\hline 4 & Guliran (scroll) yang banyak memudahkan untuk mencari informasi. &
\end{tabular}




\begin{tabular}{|c|l|c|}
\hline \multicolumn{2}{|l|}{ Aspek visual dan desain interaksi } & C1 \\
\hline 5 & Huruf (font) yang digunakan memudahkan pembacaan teks. & C2 \\
\hline 6 & $\begin{array}{l}\text { Perpaduan warna yang digunakan memudahkan untuk mencari } \\
\text { informasi. }\end{array}$ & C3 \\
\hline 7 & Pembacaan teks mudah, tanpa harus digeser dan zoom & D1 \\
\hline Aspek navigasi & D2 \\
\hline 8 & Kotak pencarian (Search) mudah ditemukan dan digunakan. & $\begin{array}{l}\text { Anda mudah untuk kembali ke halaman home bila sedang berada di } \\
\text { halaman web lainnya. }\end{array}$ \\
\hline 10 & Bidang input teks mudah digunakan. & D3 \\
\hline
\end{tabular}

Tabel 1. Kode item kuesioner variabel usability web mobile

Pada variabel persepsi pengguna, delapan kata sifat yang telah dipilih kemudian dikodekan sebagai berikut :

\begin{tabular}{|c|c|c|c|c|}
\hline \multirow{2}{*}{ No. } & \multirow{2}{*}{ Deskripsi } & \multicolumn{2}{|c|}{ Kata Sifat } & \multirow{2}{*}{ Kode } \\
\hline & & Positif & Negatif & \\
\hline 1 & Persepsi tentang layout & Sederhana & Rumit & P1 \\
\hline 2 & $\begin{array}{l}\text { Persepsi tentang kontras antara teks dan } \\
\text { background }\end{array}$ & Baik & Buruk & $\mathrm{P} 2$ \\
\hline 3 & $\begin{array}{l}\text { Persepsi tentang warna yang diterapkan pada } \\
\text { web }\end{array}$ & Cerah & Kusam & P3 \\
\hline 4 & $\begin{array}{l}\text { Persepsi tentang keseluruhan tampilan visual } \\
\text { web }\end{array}$ & Indah & Jelek & P4 \\
\hline 5 & $\begin{array}{l}\text { Persepsi tentang pilihan menu yang disediakan } \\
\text { oleh web }\end{array}$ & Menarik & Bosan & P5 \\
\hline 6 & $\begin{array}{l}\text { Persepsi tentang kepuasan pengguna pada saat } \\
\text { berinteraksi dengan web }\end{array}$ & Nyaman & $\begin{array}{l}\text { Tidak } \\
\text { Nyaman }\end{array}$ & P6 \\
\hline 7 & Persepsi tentang waktu akses web & Cepat & Lambat & P7 \\
\hline 8 & $\begin{array}{l}\text { Persepsi tentang interaksi pengguna dengan } \\
\text { web }\end{array}$ & Mudah & Sulit & P8 \\
\hline
\end{tabular}

Tabel 2. Kode item kuesioner variabel persepsi pengguna

\section{Pembahasan}

\section{Web Mobile Usability}

Pengalaman pengguna menjadi penting pada perangkat mobile dan itu adalah salah satu faktor utama yang menentukan apakah sebuah situs memiliki tingkat konversi yang tinggi. Kegunaan perangkat mobile juga mencakup aspek aksesibilitas dan dapat menentukan berapa banyak orang berinteraksi dengan situs, berapa banyak dari mereka melakukan transaksi jual/beli, atau berapa banyak keuntungan dari interaksi pengguna, terlepas dari perangkat yang mereka gunakan. Ada beberapa kendala yang harus dipertimbangkan pengembang dan desainer ketika merancang dan mengembangkan aplikasi atau situs untuk mobile. 
Untuk merancang pengalaman pengguna mobile yang lebih baik sangat penting untuk memahami perilaku mereka dalam kaitannya dengan pengalaman mobile yang akan diberikan dan dalam kaitannya dengan seluruh pengalaman web mobile. Sebagai aturan umum, jika ingin memberikan pengalaman yang terbaik untuk pengguna perangkat mobile, pengembang dan desainer harus berpikir sebagai pengguna mobile. Apa yang pengguna cari dari pengalaman mobile? Apa tujuan yang ingin mereka capai? Secara umum, ketika pengguna mengakses situs web pada perangkat mobile, mereka ingin fokus pada konten yang akan membantu untuk mencapai tujuan mereka. Bahkan jika tujuan itu adalah untuk dihibur sambil menunggu bus, pengguna tidak ingin membuang waktu (atau data) untuk mencoba menelusuri ke mana mereka ingin pergi. Pengguna perangkat mobile tidak melihat layar besar dan mungkin harus berurusan dengan faktor lingkungan serta kendala perangkat. Faktor-faktor ini dapat memiliki dampak besar pada bagaimana mereka berinteraksi dengan perangkat mobile.

Tidak adanya pengalaman pengguna yang sempurna disebabkan oleh faktor selera, budaya dan pribadi yang berbeda - beda. Satu konteks saja bukan satu-satunya cara untuk menentukan bagaimana memberikan pengalaman pengguna yang baik di perangkat mobile, masih mungkin untuk menggunakan paradigma penelitian pada perilaku pengguna untuk mencari tahu apa yang ingin dilakukan pada situs mobile. Konteks fisik memungkinkan perancang untuk lebih memahami bagaimana pengguna berniat untuk memanfaatkan situs pada perangkat mobile.

Sama seperti susunan usability web desktop dan perangkat lunak lainnya, sebagian besar pertimbangan usability dalam ruang web mobile cukup masuk akal. Pengguna perangkat mobile pada dasarnya adalah pengguna web desktop yang mempunyai keterbatasan yang baru, diantaranya layar kecil, antarmuka masukan kecil, lingkungan yang berbeda - beda dan kebiasaan pengguna yang terburu-buru dan kadang terganggu. Usability disusun agar pengguna dapat memiliki pengalaman yang lebih baik pada perangkat mobile. Memahami apa yang pengguna inginkan, apa yang mereka ingin lakukan dengan web dan konteks dimana niat pengguna terhadap web yang dirancang sangat mempengaruhi keputusan desainer untuk membangun situs dan layout. Cara terbaik untuk membuat antarmuka yang user-friendly adalah memahami apa yang pengguna ingin dapatkan dari interaksi mereka dengan web, dan apa yang menjadi hambatan saat pelaksanaannya. Untuk itu PeakUsability (PeakUsability, 2011:18) menyusun pedoman usability untuk web mobile.

\section{Analisis Usability Desain Responsif Web Mobile Perguruan Tinggi}

Dari setiap item kuesioner usability ditentukan nilai rata-ratanya dan dibuatkan grafik sederhana untuk melihat signifikansi dari objek penelitian. Nilai rata - rata tersebut kemudian dikelompokkan berdasarkan aspek dari pedoman usability web mobile. 


\begin{tabular}{|c|c|c|c|c|c|c|}
\hline NO & KODE & UI & ITB & UNS & UPI & UNPAD \\
\hline 1 & A1 & 3.90 & 4.03 & 3.72 & 3.57 & 3.74 \\
\hline 2 & A2 & 3.91 & 3.59 & 3.48 & 3.43 & 3.69 \\
\hline 3 & B1 & 3.94 & 3.68 & 3.72 & 3.38 & 3.69 \\
\hline 4 & B2 & 3.60 & 3.72 & 3.49 & 3.55 & 3.57 \\
\hline 5 & C1 & 4.02 & 3.84 & 3.76 & 3.63 & 3.72 \\
\hline 6 & C2 & 3.67 & 3.92 & 3.51 & 3.52 & 3.52 \\
\hline 7 & C3 & 3.74 & 3.72 & 3.51 & 3.37 & 3.87 \\
\hline 8 & D1 & 3.83 & 3.80 & 3.48 & 3.57 & 3.71 \\
\hline 9 & D2 & 3.74 & 3.85 & 3.62 & 3.60 & 3.64 \\
\hline 10 & D3 & 3.77 & 3.67 & 3.55 & 3.60 & 3.64 \\
\hline
\end{tabular}

Tabel 3. Nilai rata - rata usability web mobile

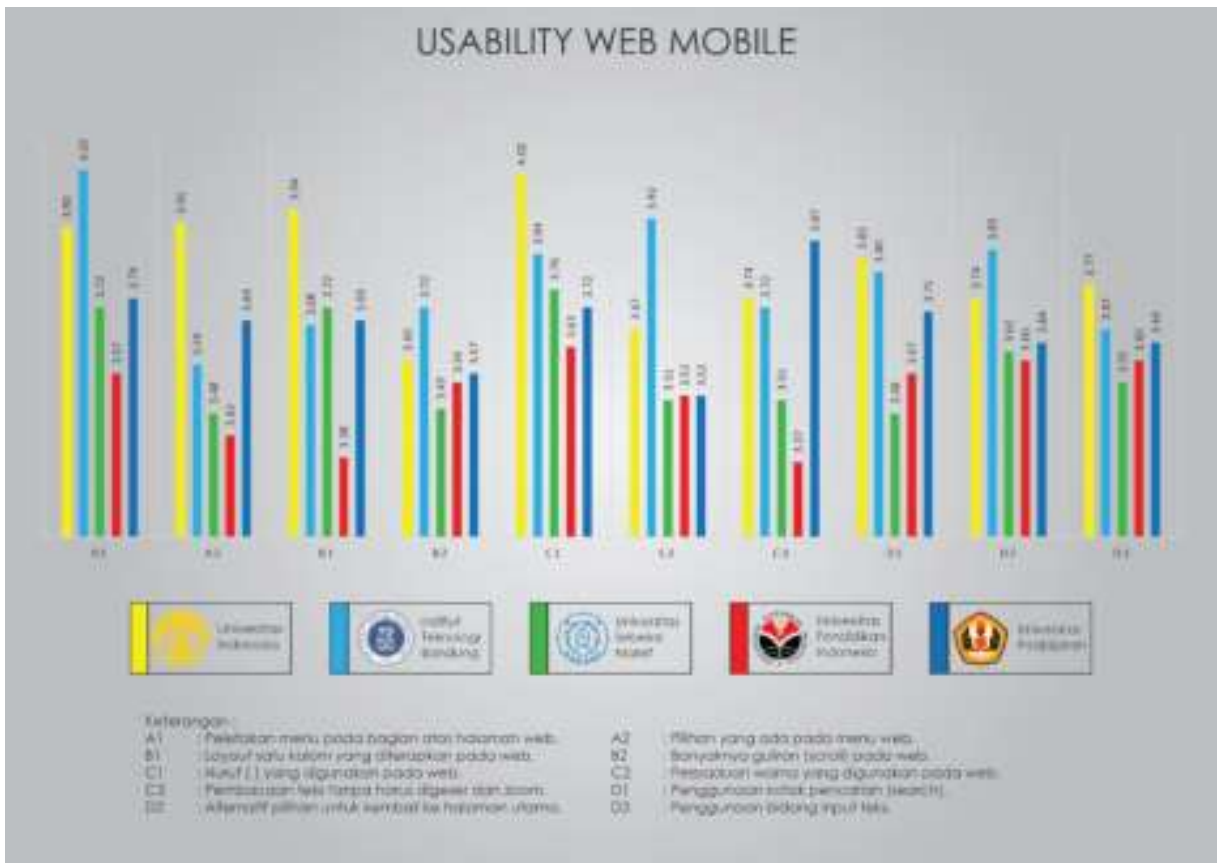

Gambar 1. Grafik nilai rata - rata tingkat usability desain responsif web mobile perguruan tinggi.

Dari analisis usability desain responsif web mobile perguruan tinggi melalui empat aspek yaitu desain tujuan mobile, layout, visual dan desain interaksi, dan navigasi yang diambil nilai rata-ratanya, didapatkan hasil bahwa web yang mempunyai tingkat usability yang paling tinggi yaitu web Universitas Indonesia. Hal ini disebabkan oleh kemudahan dalam interaksi dengan web berdasarkan font yang digunakan pada teks, pembacaan teks yang mudah tanpa harus digeser dan zoom, kotak pencarian yang mudah digunakan, dan kemudahan penggunaan bidang input teks pada web. Untuk web yang memiliki tingkat usability paling rendah yaitu web Universitas Pendidikan 
Indonesia, yang dilihat dari angka rata - rata pada kesulitan pengguna dalam berinteraksi dengan web berdasarkan alternatif pilihan menu yang disediakan pada web, layout satu kolom yang diterapkan, penggunaan font pada teks, pembacaan teks tanpa di geser dan zoom, dan dari tiga elemen usability dari aspek navigasi.

\section{Analisis Persepsi Pengguna Terhadap Desain Responsif Web Mobile Perguruan Tinggi.}

Untuk analisis persepsi pengguna juga akan ditentukan nilai rata - rata dari kata sifat pada kuesioner dan dibuatkan grafik sederhana untuk melihat signifikansi dari objek penelitian.

\begin{tabular}{|c|c|c|c|c|c|c|}
\hline NO & KODE & UI & ITB & UNS & UPI & UNPAD \\
\hline 1 & P1 & 3.78 & 3.93 & 3.91 & 3.62 & 3.89 \\
\hline 2 & P2 & 3,80 & 4.15 & 3.87 & 3.70 & 3.71 \\
\hline 3 & P3 & 3.79 & 4.00 & 3.76 & 3.68 & 3.78 \\
\hline 4 & P4 & 3.67 & 3.87 & 3.47 & 3.43 & 3.62 \\
\hline 5 & P5 & 3.61 & 3.84 & 3.47 & 3.39 & 3.70 \\
\hline 6 & P6 & 3.74 & 3.67 & 3.38 & 3.43 & 3.51 \\
\hline 7 & P7 & 3.56 & 3.66 & 3.51 & 3.56 & 3.78 \\
\hline 8 & P8 & 3.60 & 3.59 & 3.55 & 3.71 & 3.84 \\
\hline
\end{tabular}

Tabel 4. Nilai rata - rata persepsi pengguna

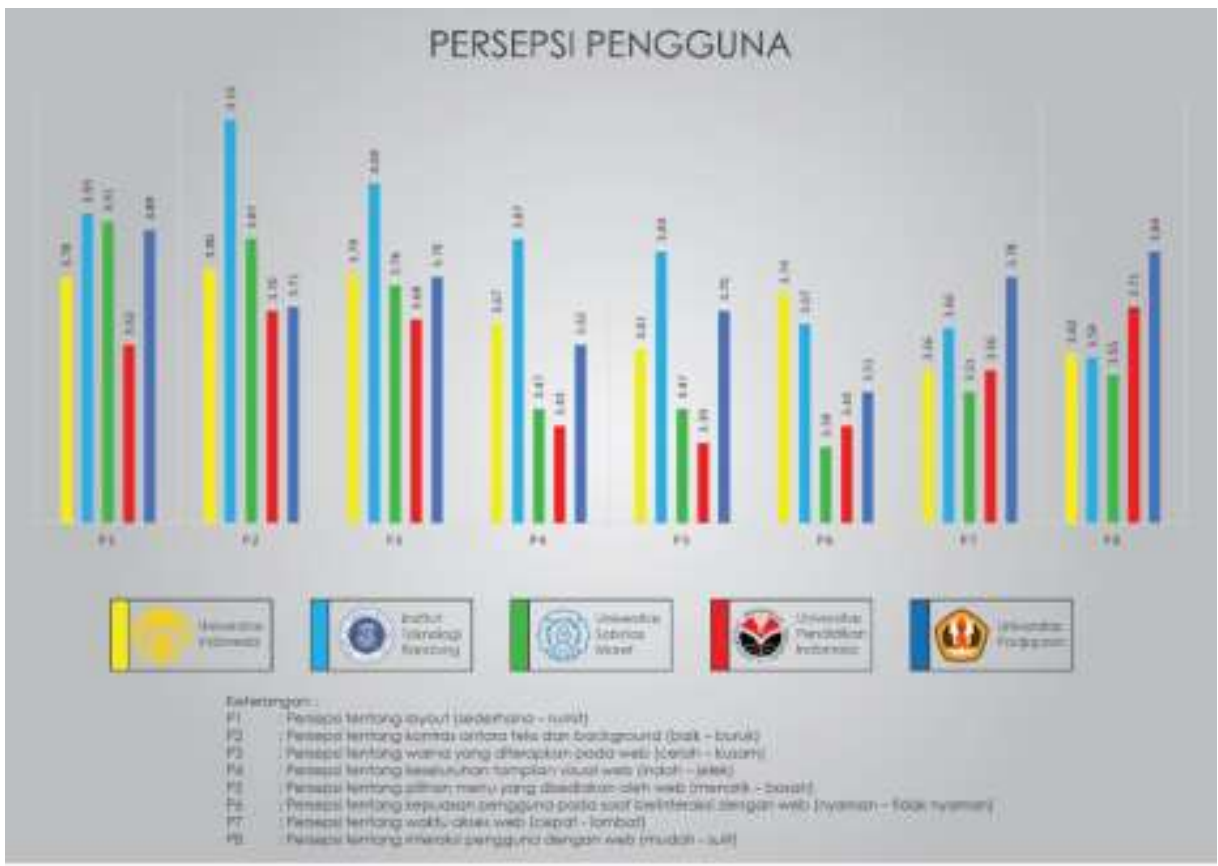

Gambar 2. Grafik nilai rata - rata persepsi pengguna terhadap desain responsif web mobile perguruan tinggi. 
Dari analisis persepsi pengguna terhadap desain responsif web mobile perguruan tinggi yang didapatkan dari perhitungan nilai rata - rata dari seluruh kata sifat yang telah dipilih, didapatkan hasil bahwa web Institut Teknologi Bandung yang memiliki persepsi paling positif dari pengguna. Dilihat dari nilai rata - rata tertinggi persepsi baik pada kontras teks dan background, persepsi cerah pada warna yang digunakan web, persepsi indah pada tampilan visual web, persepsi menarik pada alternatif pilihan yang disediakan pada menu web. Untuk web yang memiliki persepsi yang rendah adalah web Universitas Pendidikan Indonesia digambarkan oleh nilai rata - rata dari seluruh persepsi yang diujikan.

Uji korelasi hubungan positif antara tingkat usability web mobile dengan persepsi pengguna dalam aspek visual dan desain interaksi

\begin{tabular}{|c|c|c|c|c|c|c|c|c|c|c|c|}
\hline \multicolumn{12}{|c|}{ Correlations } \\
\hline & & T_C & T_P1 & T_P2 & T_P3 & T_P4 & T_P5 & T_P6 & T_P7 & T_P8 & T_P \\
\hline \multirow[t]{3}{*}{ T_C } & $\begin{array}{l}\text { Pearson } \\
\text { Correlation }\end{array}$ & 1 & $.416^{\prime \prime}$ & $.625 "$ & $.601^{\prime \prime}$ & $.742^{\prime \prime}$ & $.640^{\prime \prime}$ & $.591 "$ & $.464^{\prime \prime}$ & $.579^{\prime \prime \prime}$ & $.819^{\prime \prime}$ \\
\hline & $\begin{array}{l}\text { Sig. (2- } \\
\text { tailed) }\end{array}$ & & .000 & .000 & .000 & .000 & .000 & .000 & .000 & .000 & .000 \\
\hline & $\mathrm{N}$ & 87 & 87 & 87 & 87 & 87 & 87 & 87 & 87 & 87 & 87 \\
\hline
\end{tabular}

Gambar 3. Hasil pengujian menggunakan korelasi Pearson melalui aplikasi SPSS.

\section{Keterangan :}

T_C : Total dari aspek visual dan desain interaksi

T_P1 : Total dari persepsi tentang layout (sederhana - rumit)

T_P2 : Total dari persepsi tentang kontras antara teks dan background (baik - buruk)

T_P3 : Total dari persepsi tentang warna yang diterapkan pada web (cerah - kusam)

T_P4 : Total dari persepsi tentang keseluruhan tampilan visual web (indah - jelek)

T_P5 : Total dari persepsi tentang pilihan menu yang disediakan oleh web (menarik - bosan)

T_P6 : Total dari persepsi tentang kepuasan pengguna pada saat berinteraksi dengan web (nyaman - tidak nyaman)

T_P7 : Total dari persepsi tentang waktu akses web (cepat - lambat)

T_P8 : Total dari persepsi tentang interaksi pengguna dengan web (mudah - sulit)

T_P : Total dari keseluruhan persepsi pengguna

Berdasarkan pengujian yang dilakukan didapatkan hasilkan bahwa korelasi untuk P1 dengan nilai sebesar 0,416 termasuk kategori sedang. Jadi terdapat hubungan yang netral antara aspek visual dan desain interksi dengan kesan sederhana pada layout web mobile perguruan tinggi. Pada P2 ditemukan korelasi dengan nilai sebesar 0,625 termasuk kategori kuat. Jadi terdapat hubungan yang besar antara aspek visual dan desain interaksi dengan kesan baik pada kontras antara teks dan background web mobile perguruan tinggi. Persepsi P3 mendapat nilai korelasi sebesar 0,601 yang termasuk kategori kuat. Jadi terdapat hubungan yang besar antara aspek visual dan desain interaksi dengan kesan kecerahan pada penerapan warna dalam web mobile 
perguruan tinggi. Nilai korelasi persepsi P4 yaitu sebesar 0,742 dan termasuk kategori kuat. Jadi terdapat hubungan yang besar antara aspek visual dan desain interaksi dengan kesan keindahan tampilan visual web mobile perguruan tinggi.

Untuk persepsi P5 mendapatkan nilai korelasi sebesar 0,640 artinya masuk dalam kategori kuat, dengan begitu terdapat hubungan yang besar antara aspek visual dan desain interaksi dengan kesan menarik pada tampilan visual web mobile perguruan tinggi. Pada persepsi P6, nilai korelasinya sebesar 0.591 yang artinya masuk dalam kategori sedang. Sehingga terdapat hubungan yang netral antara aspek visual dan desain interaksi dengan kesan kenyamanan pada tampilan visual web mobile perguruan tinggi. Persepsi P7 mendapat nilai korelasi sebesar 0,464 yang artinya masuk dalam kategori sedang. Jadi terdapat hubungan yang netral antara aspek visual dan desain interaksi dengan kecepatan waktu akses web mobile perguruan tinggi. Nilai persepsi P8 ditunjukkan dengan nilai korelasi sebesar 0,579 dan masuk dalam kategori sedang. Jadi terdapat hubungan yang netral antara aspek visual dan desain interaksi dengan kemudahan dalam interaksi dengan web mobile perguruan tinggi. Jadi secara keseluruhan korelasi antara nilai T_C dan T_P sebesar 0,819, termasuk dalam kategori sangat kuat. Dapat dikatakan terdapat hubungan yang sangat positif antara aspek visual dan desain interaksi dengan persepsi pengguna. Dan pengaruh antara keduanya dapat dilihat dengan nilai korelasi determinasi yaitu 0,671 yang diartikan pengaruh tingkat usability desain responsif web mobile perguruan tinggi pada aspek visual dan desain interaksi terhadap persepsi pengguna sebesar $67,1 \%$ dan sisanya 32,9\% dipengaruhi oleh faktor lain.

\section{Kesimpulan}

Tingkat usability desain responsif web mobile perguruan tinggi melalui empat aspek yaitu desain tujuan mobile, layout, visual dan desain interaksi, dan navigasi yang diambil nilai rata-ratanya, didapatkan hasil bahwa web yang mempunyai tingkat usability yang paling tinggi yaitu web Universitas Indonesia. Hal ini disebabkan oleh kemudahan dalam interaksi dengan web berdasarkan font yang digunakan pada teks, pembacaan teks yang mudah tanpa harus digeser dan zoom, kotak pencarian yang mudah digunakan, dan kemudahan penggunaan bidang input teks pada web. Tingkat usability paling rendah yaitu web Universitas Pendidikan Indonesia, yang dilihat dari angka rata - rata pada kesulitan pengguna dalam berinteraksi dengan web berdasarkan alternatif pilihan menu yang disediakan pada web, layout satu kolom yang diterapkan, penggunaan font pada teks, pembacaan teks tanpa di geser dan zoom, dan dari tiga elemen usability dari aspek navigasi.

Berdasarkan persepsi pengguna perangkat mobile, web perguruan tinggi mempunyai tampilan layout yang sederhana, navigasi yang mudah digunakan, dan waktu akses yang cepat. Hal ini berarti desain responsif yang diterapkan pada web perguruan tinggi 
mempunyai kesan yang positif dari pengguna, sehingga membuat pengguna nyaman pada saat berinteraksi dengan web.

Penelitian ini menemukan bahwa tingkat usability pada web perguruan tinggi memiliki pengaruh yang cukup besar terhadap persepsi pengguna dalam segi elemen visual dan interaksi web. Selain itu tingkat usability juga mempengaruhi persepsi pengguna dalam hal navigasi web perguruan tinggi, pengaruh tingkat usability desain responsif web mobile perguruan tinggi dengan persepsi pengguna berdasarkan aspek visual dan interaksi mempunyai nilai sebesar $67,1 \%$.

\section{Referensi}

Bloomer, C. (1976): Principles of visual perception, New York: Van Nostrand Reinhold Company.

Gapinski, D., \& Runyon, E. (2012): Responsive design in higher education. mStoner. http://youtu.be/qGPwkDtQrxU, diakses pada tanggal 2 Desember 2013 pukul 16.36 WIB.

Gaunt, M. (2014): Navigation and action patterns https://developers.google.com/web/fundamentals/layouts/navigationpatterns/?hl=en, diakses pada tanggal 12 Februari 2015 pukul 10.27 WIB.

Joly, K. (2012): One Design to rull them all? Responsive web design in higher education. University Business, 15(2), 49.

Keynote. (2012): 2012 Mobile user survey. http://www.slideshare.net/keynote_systems/keynote-mobile-user-survey-1h2012, diakses pada tanggal 9 Februari 2015 09.29 WIB.

Marcotte, E. (2011): Responsive Web Design. New York: A Book Apart.

Media Queries. (2011): Choicesresponse http://mediaqueri.es/cho/, diakses pada tanggal 4 Maret 2015 pukul 10.43 WIB.

Nielsen, J. (1999): Designing Web Usability. Barkeley: New Riders.

Nielsen, J, Loranger, Hoa. (2006): Prioritizing Web Usability. Barkeley: New Riders. Seward, Dan. (2011): Designing Usable Mobile Websites. Brisbane: Peak Usability. Sugiyono. (2013): Metode Penelitian Kombinasi (Mixed Methods). Bandung: Alfabeta. Ware, C. (2004): Information Visualization: Perception For Design. MA: Morgan Kaufmann.

Wearesocial. (2015): Digital, Social \& Mobile in 2015 http://wearesocial.net/blog/2015/01/digital-social-mobile-worldwide-2015/, diakses pada tanggal 5 Februari 2015 pukul 09.32 WIB.

Wroblewski, L. (2011): Mobile First. New York: A Book Apart.

Wroblewski, L. (2012): Multi-Device layout pattern http://www.lukew.com/ff/entry.asp?1514, diakses pada tanggal 3 Februari 2015 pukul 19.50 WIB. , http://webometrics.info www.4icu.org www.topuniversities.com semantic differential 
Fadliyani Nawir, Achmad Syarief \& Irfansyah

Pengaruh Tingkat Usability Terhadap Tampilan Visual Responsif Desain Web Mobile Perguruan Tinggi

http://psychology.ucdavis.edu/faculty_sites/sommerb/sommerdemo/scalin g/semdiff.htm 